\title{
The Effects of $\mathrm{Li}^{+}$Doping on Structure and Upconversion Luminescent Properties for $\mathrm{Bi}_{3.46} \mathrm{Ho}_{0.04} \mathrm{Yb}_{0.5} \mathrm{Ti}_{3} \mathrm{O}_{12}: x \mathrm{Li}$ Phosphors
}

\author{
Feng Ren ${ }^{1,2}$, Jinlei Zhou ${ }^{1,2}$, Dengpeng Wang ${ }^{1,2}$, Xianran Wang ${ }^{1,2}$ and Feng Gao ${ }^{1,2, *(D)}$ \\ 1 Guangxi Key Laboratory of Processing for Non-Ferrous Metals and Featured Materials, MOE Key \\ Laboratory of New Processing Technology for Non-Ferrous Metals and Materials, Guangxi University, \\ Nanning 530004, China; 1815301034@st.gxu.edu.cn (F.R.); 1915391058@st.gxu.edu.cn (J.Z.); \\ 1915391031@st.gxu.edu.cn (D.W.); 2015301071@st.gxu.edu.cn (X.W.) \\ 2 School of Resources, Environment and Materials, Guangxi University, Nanning 530004, China \\ * Correspondence: gaofeng@gxu.edu.cn
}

Citation: Ren, F.; Zhou, J.; Wang, D.; Wang, X.; Gao, F. The Effects of $\mathrm{Li}^{+}$

Doping on Structure and

Upconversion Luminescent

Properties for $\mathrm{Bi}_{3.46} \mathrm{Ho}_{0.04} \mathrm{Yb}_{0.5} \mathrm{Ti}_{3} \mathrm{O}_{12}$ : $x$ Li Phosphors. Crystals 2021, 11, 1220. https://doi.org/10.3390/

cryst11101220

Academic Editor: Pier Carlo Ricci

Received: 20 September 2021

Accepted: 5 October 2021

Published: 9 October 2021

Publisher's Note: MDPI stays neutral with regard to jurisdictional claims in published maps and institutional affiliations.

Copyright: (c) 2021 by the authors. Licensee MDPI, Basel, Switzerland. This article is an open access article distributed under the terms and conditions of the Creative Commons Attribution (CC BY) license (https:// creativecommons.org/licenses/by/ $4.0 /)$.

\begin{abstract}
A series of novel $\mathrm{Li}^{+}$doped $\mathrm{Bi}_{3.46} \mathrm{Ho}_{0.04} \mathrm{Yb}_{0.5} \mathrm{Ti}_{3} \mathrm{O}_{12}$ (BHYTO: $x \mathrm{Li}, 0 \leq x \leq 0.15$ ) upconversion phosphors were prepared through a sol-gel-sintering method. There exist three emission bands centered at $545 \mathrm{~nm}, 658 \mathrm{~nm}$, and $756 \mathrm{~nm}$ in the upconversion emission spectra at $980 \mathrm{~nm}$ excitation, corresponding to energy transitions of ${ }^{5} \mathrm{~F}_{4} /{ }^{5} \mathrm{~S}_{2} \rightarrow{ }^{5} \mathrm{I}_{8},{ }^{5} \mathrm{~F}_{5} \rightarrow{ }^{5} \mathrm{I}_{8}$ and ${ }^{5} \mathrm{~F}_{4} /{ }^{5} \mathrm{~S}_{2} \rightarrow{ }^{5} \mathrm{I}_{7}$ of $\mathrm{Ho}^{3+}$, and the upconversion emission intensity of BHYTO: $0.05 \mathrm{Li}$ is about 2.2 times stronger than that of BHYTO samples. The luminescent lifetime of the strongest emission $(545 \mathrm{~nm})$ is in the range of 45.25 to $65.99 \mu$ for the different BHYTO: $x$ Li phosphors. The energy transfers during the upconversion pumping process from $\mathrm{Yb}^{3+}$ to $\mathrm{Ho}^{3+}$ are mainly responsible for all the emissions, each belonging to a double-photon process. $\mathrm{Li}^{+}$mainly entered into the interspace sites or occupied $\mathrm{Bi}^{3+}$ sites in $\mathrm{Bi}_{4} \mathrm{Ti}_{3} \mathrm{O}_{12}$ host during the fabrication process according to its dosage, and the possibility is very low for $\mathrm{Li}^{+}$to take part in the energy transfer process directly due to its lack of matching levels with $4 \mathrm{f}$ of $\mathrm{Ho}^{3+}$ and $\mathrm{Yb}^{3+}$. However, $\mathrm{Li}^{+}$doping can not only increase the size of crystal grains to improve crystallinity through XRD analysis, but also reduced oxygen vacancies to decrease the number of quenching centers through XPS analysis. The improved crystallinity and reduced quenching centers are proposed to be the main causes for the enhanced upconversion luminescence of the $\mathrm{Li}^{+}$doped BHYTO phosphor.
\end{abstract}

Keywords: $\mathrm{Li}^{+}$ion; upconversion luminescence; luminescence enhancement; grain size

\section{Introduction}

Rare earth (RE) doped upconversion (UC) phosphors played important roles in LED [1], display [2], biological image [3], laser [4], and optical fiber [5], attracting a lot of interests to develop novel optical materials. $\mathrm{Bi}_{4} \mathrm{Ti}_{3} \mathrm{O}_{12}$ (BTO) based materials with an Aurivillius structure have been studied intensively for a long time due to their good electric properties [6], and almost all $\mathrm{RE}^{3+}$ doping has positive effects on improving its ferroelectricity of BTO [7]. Following that, the excellent photoluminescence was observed in the BTO based multifunctional materials, such as $\mathrm{Er}^{3+}, \mathrm{Tm}^{3+}, \mathrm{Ho}^{3+}, \mathrm{Yb}^{3+}$ single doped, or co-doped BTO phosphors [8]. Recently, an efficient UC phosphor of $\mathrm{Ho}^{3+}-\mathrm{Yb}^{3+}$ co-doped $\mathrm{Bi}_{3.46} \mathrm{Ho}_{0.04} \mathrm{Yb}_{0.5} \mathrm{Ti}_{3} \mathrm{O}_{12}$ (BHYTO) powder was reported [9]. There are three main reasons to contribute BTO to be a good optical host for photoluminescence: (1) $\mathrm{RE}^{3+}$ ions have a large solid solubility to substitute $\mathrm{Bi}^{3+}$ sites and can disperse evenly in BTO crystal lattice due to similar ionic radius and the same valence state as $\mathrm{Bi}^{3+}$ [10], and (2) they can stabilize oxygen in BTO crystal lattice and reduce oxygen vacancy [11], and (3) BTO has a low phonon energy and good physical and chemical stability [12].

Although a lot of $\mathrm{RE}^{3+}$ doped phosphors were designed and invented so far, only a few of them obtained practical applications because most of them have a lower luminescence efficiency. So the research on how to improve luminescence efficiency through a simple 
method has a higher value than only to find a novel phosphor. Doping of assistant ions in phosphors has been considered to be an efficient and important way in improving luminescence property [13]. $\mathrm{Li}^{+}$was the most used assistant ion in either down shifting or upconversion RE phosphors. It can enter into the host crystal lattice of these phosphors easily without destroying the original crystal structure since it has a small ion radius and simple electron configuration. However, the enhanced amplitude and initial causes for luminescence improvement in these RE phosphors were usually different, even for the same phosphor fabricated with different methods. For examples, the emission intensities of $\mathrm{Li}^{+}$doped $\mathrm{CaMoO}_{4}: \mathrm{Er}^{3+}, \mathrm{Yb}^{3+}[14], \mathrm{Gd}_{2} \mathrm{O}_{3}: \mathrm{Yb}^{3+}, \mathrm{Ho}^{3+}[15]$, and $\mathrm{Y}_{2} \mathrm{O}_{3}: \mathrm{Eu}^{3+}$ [16] were reported to be 83,10, and 1.2 times higher than those of phosphors without $\mathrm{Li}^{+}$doping. At present, there are many proposals to illustrate the role of $\mathrm{Li}^{+}$in the process of luminescence enhancement, such as local crystal field distortion [14], charge compensation [17], change in morphology [18], and improved crystallinity and increased grain size [19]. However, some of these proposals were short of data support or not discussed in detail.

\section{Experiment}

In the formula of $\mathrm{Bi}_{3.46} \mathrm{Ho}_{0.04} \mathrm{Yb}_{0.5} \mathrm{Ti}_{3} \mathrm{O}_{12}: x \mathrm{Li}(x=0,0.02,0.05,0.10,0.15)$, and the mole ratio of $\mathrm{Li}, \mathrm{Bi}, \mathrm{Ho}, \mathrm{Yb}$, and Ti is equal to $x: 3.46: 0.04: 0.5: 3$, where $x$ denotes nominal $\mathrm{Li}$ doped content $\left(\mathrm{C}_{\mathrm{N}}\right)$ in $\mathrm{Bi}_{3.46} \mathrm{Ho}_{0.04} \mathrm{Yb}_{0.5} \mathrm{Ti}_{3} \mathrm{O}_{12}: x \mathrm{Li}$. During the fabrication of $\mathrm{Bi}_{3.46} \mathrm{Ho}_{0.04} \mathrm{Yb}_{0.5} \mathrm{Ti}_{3} \mathrm{O}_{12}: x \mathrm{Li}$ phosphors, $\mathrm{LiNO}_{3}$ (99\%, Macklin, Shanghai, China), $\mathrm{Bi}\left(\mathrm{NO}_{3}\right)_{3} \cdot 5 \mathrm{H}_{2} \mathrm{O}\left(99 \%\right.$, SCRC, Shanghai, China), $\mathrm{Ho}\left(\mathrm{NO}_{3}\right)_{3} \cdot 6 \mathrm{H}_{2} \mathrm{O}(99.99 \%$, Rknerc, Shanghai, China), $\mathrm{Yb}\left(\mathrm{NO}_{3}\right)_{3} \cdot 5 \mathrm{H}_{2} \mathrm{O}\left(99.99 \%\right.$, Rknerc, Shanghai, China) and $\mathrm{Ti}\left(\mathrm{OC}_{4} \mathrm{H}_{9}\right)_{4}$ (AR, Macklin, Shanghai, China) were used as the precursors of $\mathrm{Li}, \mathrm{Bi}, \mathrm{Ho}, \mathrm{Yb}$, and Ti ions, respectively. $\mathrm{Ho}, \mathrm{Yb}$, and Ti precursors were weighed according to stoichiometry of the formula of $\mathrm{Bi}_{3.46} \mathrm{Ho}_{0.04} \mathrm{Yb}_{0.5} \mathrm{Ti}_{3} \mathrm{O}_{12}: x \mathrm{Li}$, and $\mathrm{Bi}$ and $\mathrm{Li}$ precursors exceeded $15 \%$ and $10 \%$ to supplement $\mathrm{Bi}$ and $\mathrm{Li}$ loss because both of them can partly volatilize during high-temperature treatment [20]. At first, the weighted $\mathrm{Li}, \mathrm{Bi}, \mathrm{Ho}, \mathrm{Yb}$ precursors were put into a beaker, and then $15 \mathrm{~mL}$ acetic acid (AR, Macklin, Shanghai, China) was added rapidly, followed by heated under $55{ }^{\circ} \mathrm{C}$ and stirred for $15 \mathrm{~min}$, and then cooled down to room temperature to obtain solution denoted as A liquid. $1.85 \mathrm{~mL}$ tetrabutyl titanate (AR, Macklin, Shanghai, China) was weighted and added into the other beaker containing $15 \mathrm{~mL}$ 2-methoxyethanol (AR, Macklin, Shanghai, China), and then stirred for 15 min to form B liquid. Subsequently, the B liquid was dropped into the A liquid gradually and stirred at $550 \mathrm{rpm}$ for $2 \mathrm{~h}$ simultaneously under room temperature, and $0.06 \mathrm{Mol} / \mathrm{L}$ precursor solution with a golden color was obtained. The solution was dried in an oven at $80^{\circ} \mathrm{C}$ until a solid gel was formed, and then sintered at $800^{\circ} \mathrm{C}$ for $3 \mathrm{~h}$ in a muff furnace followed by cooling to room temperature under air atmosphere. The shape of the sintered product is fluffy, so they were ground in an agate mortar for 5 min to obtain the final BHYTO: $x$ Li phosphor powders.

XRD (Rigaku D/MAX 2500V with a Cu K $\alpha$ target, Rigaku, Tokyo, Japan) was performed to analyze phase structure of the samples, and the operated voltage and current are $40 \mathrm{KV}$ and $100 \mathrm{~mA}$, and the scanning range is from $10^{\circ}$ to $60^{\circ}$ with $5^{\circ} / \mathrm{min}$ scanning speed, and the scanning step is 0.020 . The lattice parameter and cell volume were calculated automatically through Jade 6.5 software based on the measured XRD data. Inductively coupled plasma emission spectrum (ICPMS Agilent 7700s, Agilent, Santa Clara, CA, USA) was used to assess $\mathrm{Li}^{+}$practical content in the samples. SEM (Gemini Sigma 300/VP, Zeiss, Oberkochen, Germany) was used to analyze the morphology of the samples, operated at $5 \mathrm{kV}$ with a standard beam current, and EDS to analyze elemental compositions of the samples. TEM (Titan G260-300, FEI Company, Hillsboro, OR, USA) was used to observe the morphological characteristics at high magnification. XPS (ESCALAB 250XI, Thermo Fisher Scientific, Waltham, MA, USA) was used to analyze the effects of $\mathrm{Li}^{+}$doping on the structure and valance state of elements, and full spectrum scanning was performed in the range of 0 to $1000 \mathrm{eV}$ with carbon peak correction at $284.6 \mathrm{eV}$ before this analysis. Sample particle size was measured by Zeta potential (NanoBrook Omni, Brookhaven Instruments, Holtsville, NY, USA), and at the beginning of it, an appropriate amount of sample powders 
were placed in alcohol for ultrasound for $5 \mathrm{~min}$ to obtain a suspension with a concentration of about $0.6 \mathrm{mg} / \mathrm{mL}$ for measurement, and each sample was measured three times. An integrated fluorescence spectrometer (FluoroLog-3, Horiba, Kyoto, Japan) was used to measure the PLS and decay lifetime for the phosphors with a low noise $980 \mathrm{~nm}$ laser (MDL-III-980-2W, CNI Lasers, Changchun, China) as the pumping source. Note that all the samples had been dried at $120^{\circ} \mathrm{C}$ for $2 \mathrm{~h}$ in a vacuum drying oven before the tests of the optical properties.

\section{Results and Discussion}

ICPMS measurement was performed to grasp whether $\mathrm{Li}^{+}$was successfully doped into the fabricated BHYTO: $x \mathrm{Li}$ samples, and the results were shown in Table 1 . The detected $\mathrm{Li}^{+}$content $\left(C_{\mathrm{D}}\right)$ in the final sintered products is less than that of the doped $\mathrm{Li}^{+}$ content $\left(C_{\mathrm{P}}\right)$ in all the samples before sintering due to the volatilization of $\mathrm{Li}^{+}$. The detected $\mathrm{Li}^{+}$content $\left(C_{\mathrm{D}}\right)$ can be considered as $\mathrm{Li}^{+}$practical content in the final compound of the phosphors ignoring measurement error. $C_{D}$ values are $1.70 \%, 4.88 \%, 9.92 \%$, and $14.93 \%$ for the BHYTO: $x$ Li phosphors with $x$ equal to $0.02,0.05,0.10$, and 0.15 , respectively, and corresponding Li doping efficiencies $\left(\eta_{\mathrm{D}}\right)$ are $77.27 \%, 88.73 \%, 90.18 \%$, and $90.48 \%$. The values of $C_{\mathrm{D}}$ and $\eta_{\mathrm{D}}$ increased with the increase in absolute mass for excessive $\mathrm{Li}^{+}$dosage. Note that $\eta_{\mathrm{D}}$ was defined as the ratio of $C_{\mathrm{D}}$ to doped $\mathrm{Li}^{+}$content $\left(C_{\mathrm{P}}\right)$. The results suggest that excessive dosage of $10 \% \mathrm{Li}^{+}$for the raw materials during the fabrication process is available. For the convenience of description, the nominal Li doped content was used to express $\mathrm{Li}^{+}$content in all the BHYTO: $x \mathrm{Li}$ phosphors.

Table 1. The results of ICPMS measurement for Li content in BHYTO: $x$ Li samples $(x=0.02,0.05$, 0.10 , and 0.15 ).

\begin{tabular}{cccccc}
\hline Sample No. & Sample Names & $\left.\boldsymbol{C}_{\mathbf{N}} \mathbf{( m o l} \%\right)$ & $C_{\mathbf{P}}(\mathbf{m o l} \%)$ & $\left.C_{\mathbf{D}} \mathbf{( m o l} \%\right)$ & $\eta_{\mathrm{D}} \mathbf{( \% )}$ \\
\hline 1 & BHYTO: 0.02Li & 2 & 2.2 & 1.70 & 77.27 \\
2 & BHYTO: 0.05Li & 5 & 5.5 & 4.88 & 88.73 \\
3 & BHYTO: 0.10Li & 10 & 11 & 9.92 & 90.18 \\
4 & BHYTO: 0.15Li & 15 & 16.5 & 14.93 & 90.48 \\
\hline
\end{tabular}

Notes: Nominal $\mathrm{Li}^{+}$content $\left(C_{\mathrm{N}}\right)$, doped $\mathrm{Li}^{+}$content $\left(C_{\mathrm{P}}\right)$ in the samples before sintering, detected $\mathrm{Li}^{+}$content $\left(C_{\mathrm{D}}\right)$ in the sintered products and $\mathrm{Li}^{+}$doping efficiency $\left(\eta_{\mathrm{D}}\right)$ during the whole fabrication process.

In order to obtain the structural information about phase, crystallinity, and crystal distortion of BHYTO: $x$ Li phosphors, XRD was performed and the results were shown in Figure 1a. It can be seen that the phosphors consisted of dominant orthorhombic perovskite $\mathrm{Bi}_{4} \mathrm{Ti}_{3} \mathrm{O}_{12}$ phase and a small amount of pyrochlore $\mathrm{Bi}_{2} \mathrm{Ti}_{2} \mathrm{O}_{7}$ phases, and no other phase, such as $\mathrm{Li}_{2} \mathrm{O}$ or $\mathrm{Li}_{2} \mathrm{TiO}_{3}$, detected, suggesting that $\mathrm{Li}^{+}$entered into the crystal lattice of bismuth titanates. It was reported that the radius of $\mathrm{Bi}^{3+}, \mathrm{Ho}^{3+}, \mathrm{Yb}^{3+}$, and $\mathrm{Li}^{+}$ was $0.103 \mathrm{~nm}, 0.090 \mathrm{~nm}, 0.087 \mathrm{~nm}$, and $0.076 \mathrm{~nm}$, respectively [21]. The diffraction peaks of pristine BHYTO without $\mathrm{Li}^{+}$doping shifted toward larger angle in comparison with pure $\mathrm{Bi}_{4} \mathrm{Ti}_{3} \mathrm{O}_{12}$ phase (Card no. 35-0795), as shown in Figure $1 \mathrm{~b}$. $\mathrm{Ho}^{3+}$ and $\mathrm{Yb}^{3+}$ are inclined to substitute $\mathrm{Bi}^{3+}$ site in $\mathrm{Bi}_{4} \mathrm{Ti}_{3} \mathrm{O}_{12}$ [22] because of the same valence and close ion radius, and the substitution by smaller ion radius can result in crystal shrink. However, the diffraction peaks shifted towards smaller angle for BHYTO: 0.02Li sample compared to BHYTO samples, and then shifted towards larger angle gradually with further increase in $\mathrm{Li}^{+}$content. The possible reason is that $\mathrm{Li}^{+}$ions first entered into the interspaces of crystal lattice when its dosage was low and induced the expansion of the crystal cell, resulting in the shifts of diffraction peaks towards smaller angle. However, with the increase in $\mathrm{Li}^{+}$dosage, the amounts of available interspaces in BHYTO crystal were reduced little by little, and $\mathrm{Li}^{+}$began to occupy $\mathrm{Bi}^{3+}$ sites, causing volumetric shrinkage of the crystal cell and resulting in the shifts of diffraction peak towards a larger angle. Figure 1c shows the volume $\left(V_{C}\right)$ of crystal cell and grain sizes $\left(D_{C}\right)$ of crystal grains for the BHYTO: $x \mathrm{Li}$ phosphors with various $\mathrm{Li}^{+}$content based on the XRD data of Figure $1 \mathrm{a}$. The $V_{\mathrm{C}}$ values first increased and then decreased while the $D_{C}$ increased monotonously with the increase 
in $\mathrm{Li}^{+}$content in the BHYTO: $x \mathrm{Li}$ phosphors, and the $D_{C}$ values were calculated to be about $34.59 \mathrm{~nm}, 37.36 \mathrm{~nm}, 38.33 \mathrm{~nm}, 45.74 \mathrm{~nm}$, and $48.17 \mathrm{~nm}$ for the BHYTO: $x$ Li samples with $x$ equal to $0,0.02,0.05,0.1$, and 0.15 , respectively, according to famous Scherrer formula.
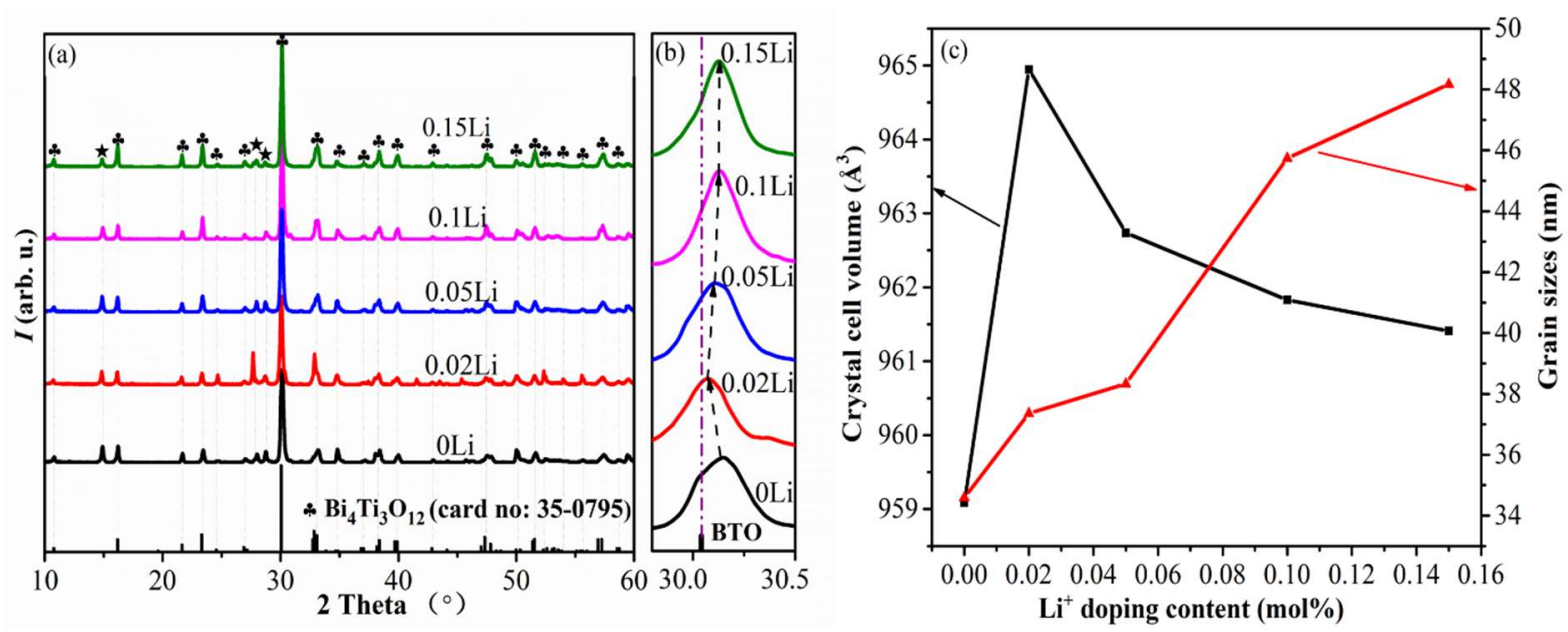

Figure 1. (a) XRD pattern, (b) an enlarged XRD graph in the range of $2 \theta=29.8^{\circ}-30.5^{\circ}$, and (c) the volume of crystal cell and grain sizes of BHYTO: $x$ Li phosphors.

For an Aurivillius structured material, the lattice distortion and strain are usually expressed by the ratios of crystal parameters, that is, b/a and c/a, respectively, and the ratios increased with the increase in crystal distortion and strain increases [23]. Compared to $\mathrm{Li}^{+}$undoped BHYTO, the degree of crystal distortion and strain were relieved significantly in $\mathrm{Li}^{+}$doped BHYTO: $x \mathrm{Li}$ phosphors, because the ratio of $\mathrm{b} / \mathrm{a}$ and $\mathrm{c} / \mathrm{a}$ decreases gradually. However, the reduced full width at half maxima (FWHM), shown as Table 2, and increased grain sizes imply an enhanced crystallization in the $\mathrm{Li}^{+}$doped samples. It was reported that $\mathrm{Li}_{2} \mathrm{O}$ can not only act as a flux to lower sintering temperature and promote the elemental diffusion so as to increase density and grain size of glass [24] and ceramics [25], but also act as catalyst to facilitate the synthesis of composite oxide [26], which could improve crystallization of products.

Table 2. The crystal parameters and FWHM for the BHYTO: $x$ Li phosphors.

\begin{tabular}{ccccc}
\hline Sample Names & $\mathbf{a}(\AA)$ & $\mathbf{b}(\AA)$ & $\mathbf{c}(\AA)$ & FWHM $(\% / \mathbf{r a d})$ \\
\hline BHYTO:0Li & 5.3930 & 5.4229 & 32.7941 & $0.263 / 0.00459$ \\
BHYTO:0.02Li & 5.4081 & 5.4367 & 32.8188 & $0.243 / 0.00424$ \\
BHYTO:0.05Li & 5.4011 & 5.4298 & 32.8278 & $0.237 / 0.00414$ \\
BHYTO:0.1Li & 5.4035 & 5.4266 & 32.8016 & $0.199 / 0.00347$ \\
BHYTO:0.15Li & 5.3993 & 5.4251 & 32.8219 & $0.189 / 0.00330$ \\
\hline
\end{tabular}

Figure 2 shows the SEM results for the BHYTO: $x$ Li phosphors. It can be observed that all the BHYTO: $x$ Li phosphors mainly consisted of micro-sized particles with irregular shape and most of the particles in weight had size in the range of 1 to $2 \mu \mathrm{m}$. There are some tiny particles on the surface of the micro-sized ones. EDS results show that the samples were composed of $\mathrm{Bi}, \mathrm{Yb}, \mathrm{Ho}, \mathrm{Ti}$, and $\mathrm{O}$ elements and no impurity element detected in the samples. The detected $\mathrm{C}$ element came from a graphite conductive adhesive tape used to adhere the sample powders during SEM measurement. $\mathrm{Li}^{+}$was not detected by EDS due to its low atomic number. Figure $2 \mathrm{~g}$ shows the content and average content of each element at 1 and 2 spot. It can be seen that the proportion of each element has little difference and is relatively consistent with the proportion of elements in $\mathrm{Bi}_{4} \mathrm{Ti}_{3} \mathrm{O}_{12}$. Figure $2 \mathrm{~h}$ shows histogram of particle size for the samples, the particle size of all the samples changed little and was above $1 \mu \mathrm{m}$, which was consistent with the results in SEM. 

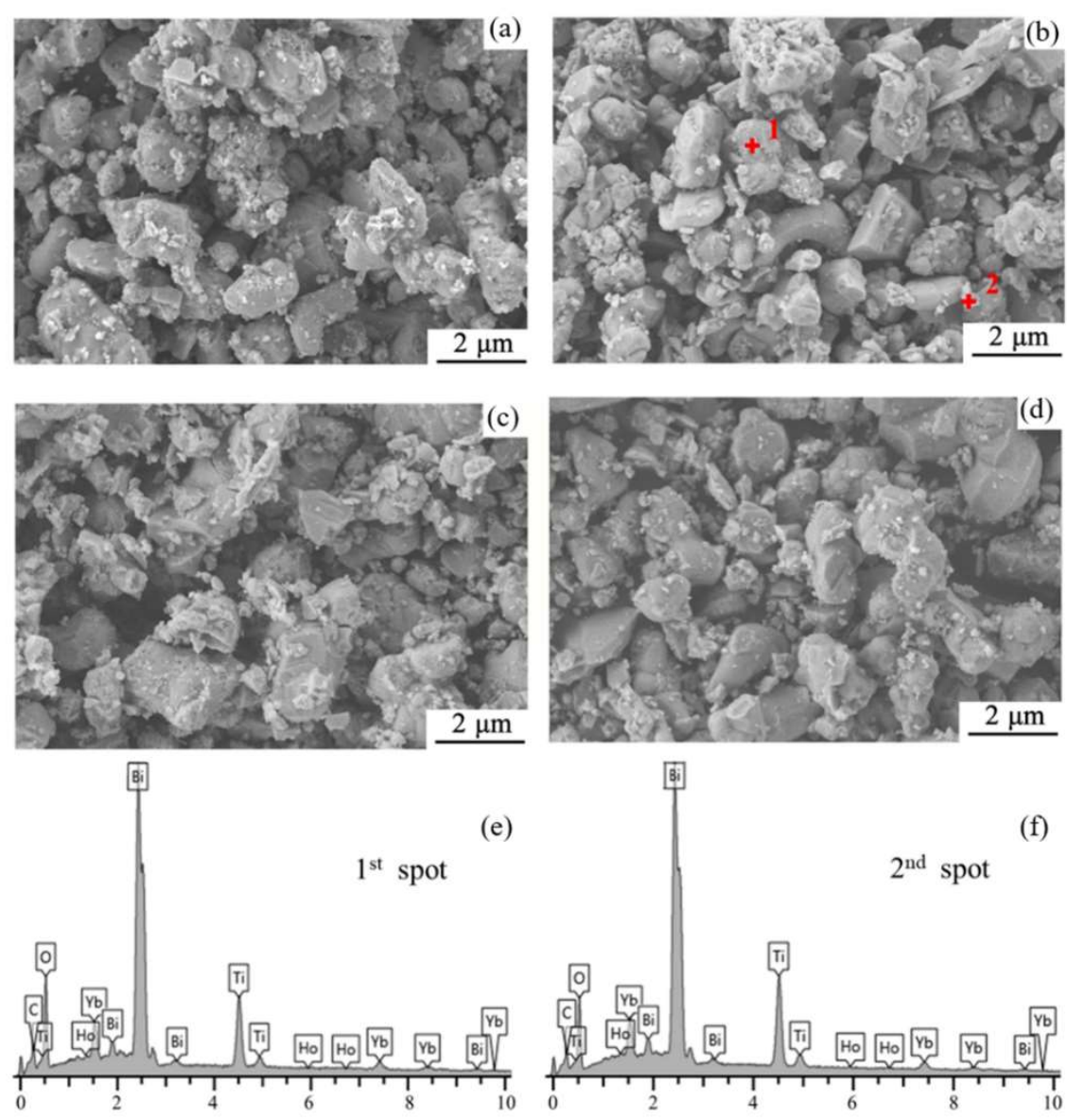

\begin{tabular}{|c|c|c|c|c|c|c|}
\hline Element & & $\mathrm{Bi}$ & $\mathrm{Ti}$ & o & $\mathrm{Yb}$ & Ho \\
\hline \multirow{2}{*}{$1^{\text {st }}$ spot } & $\mathrm{Wt} \%$ & 63.64 & 12.67 & 16.53 & 6.43 & 0.73 \\
\hline & $\mathrm{At} \%$ & 18.39 & 15.97 & 62.41 & 2.97 & 0.26 \\
\hline \multirow{2}{*}{$2^{\text {nd }}$ spot } & $\mathrm{Wt} \%$ & 63.20 & 12.84 & 17.50 & 5.92 & 0.54 \\
\hline & At $\%$ & 18.22 & 15.65 & 63.90 & 2.04 & 0.19 \\
\hline \multirow{2}{*}{ Average } & $\mathrm{Wt} \%$ & 63.42 & 12.76 & 17.01 & 6.17 & 0.64 \\
\hline & $\mathrm{At} \%$ & 18.31 & 15.81 & 63.15 & 2.50 & 0.23 \\
\hline
\end{tabular}

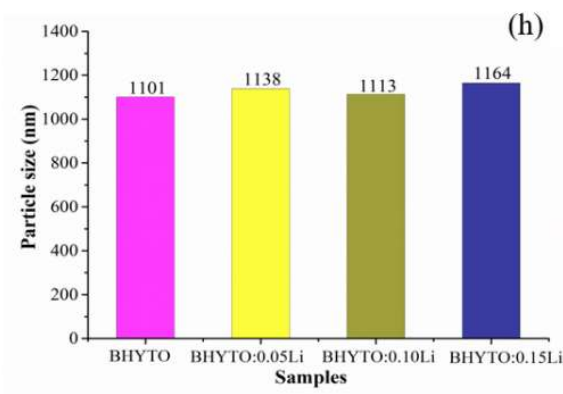

Figure 2. SEM of the BHYTO: $x$ Li samples with $x$ values equal to (a) $0,(\mathbf{b}) 0.05$, (c) 0.10 , (d) 0.15 , respectively, and (e), (f) EDS of 1st and 2nd spots in Figure 2b, (g) the elemental content in the samples of the BHYTO: 0.05Li samples, and (h) histogram of particle size for the samples.

Figure 3a shows TEM micrograph of BHYTO: 0.05Li sample with the optimal UC luminescence among all the BHYTO: $x$ Li phosphors, and the micro-sized particles have a shape of small compact blocks. Figure $3 b$ shows the selected area electron diffraction (SAED) pattern observed from c-axis direction, which presents a rectangle shape (in blue), and the length for the two intersecting edges of the rectangle is very close but not exactly the same, which is the structural feature of a typical orthorhombic crystal system. Figure $3 c$ shows high-resolution transmission electron microscopy (HRTEM) image obtained by focus to a spot on the thin edge of a grain, where a fine and delicate crystal structure with regular atomic arrangement can be observed, and the distance between two neighboring parallel crystal planes in mutually perpendicular directions are $0.271 \mathrm{~nm}$ and $0.273 \mathrm{~nm}$, corresponding to (200) and (020) crystal planes of $\mathrm{Bi}_{4} \mathrm{Ti}_{3} \mathrm{O}_{12}$, respectively [27]. Figure $3 \mathrm{~d}$ shows (020) lattice fringe obtained from a filtering method through DM software (Digital Micrograph 3.7), where more regular structure of atomic array can be observed, and the vague areas in this image denoted as 1,2, and 3 implies some defects of dislocations existed 
in the sample [28]. Figure 3e shows high-angle-annular-dark-field scanning transmission electron microscopy (HAADF-STEM) diagram and elemental distribution. The color of the object image is very bright, suggesting the phosphor contained some elements with large atomic number (i.e., Bi). The insert graphs in Figure 3 show the element compositions and distributions, and all the elements of $\mathrm{Bi}, \mathrm{Ho}, \mathrm{Yb}, \mathrm{Ti}, \mathrm{O}$ in the samples were detected except for $\mathrm{Li}$ elements due to its low atomic number, and the distributions of $\mathrm{Bi}, \mathrm{Ho}$, $\mathrm{Ti}$, and $\mathrm{O}$ are uniform and dispersed more evenly than $\mathrm{Yb}$ element.

(a)
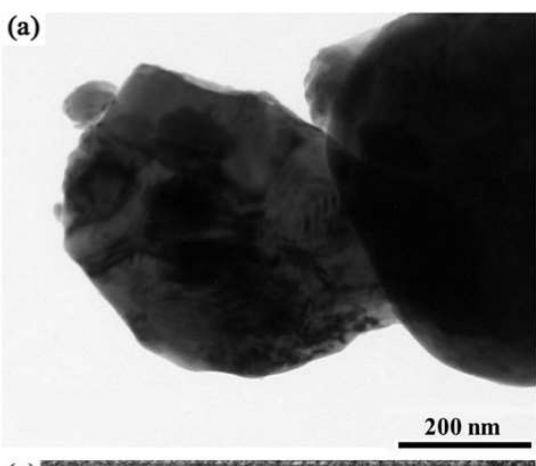

(c)
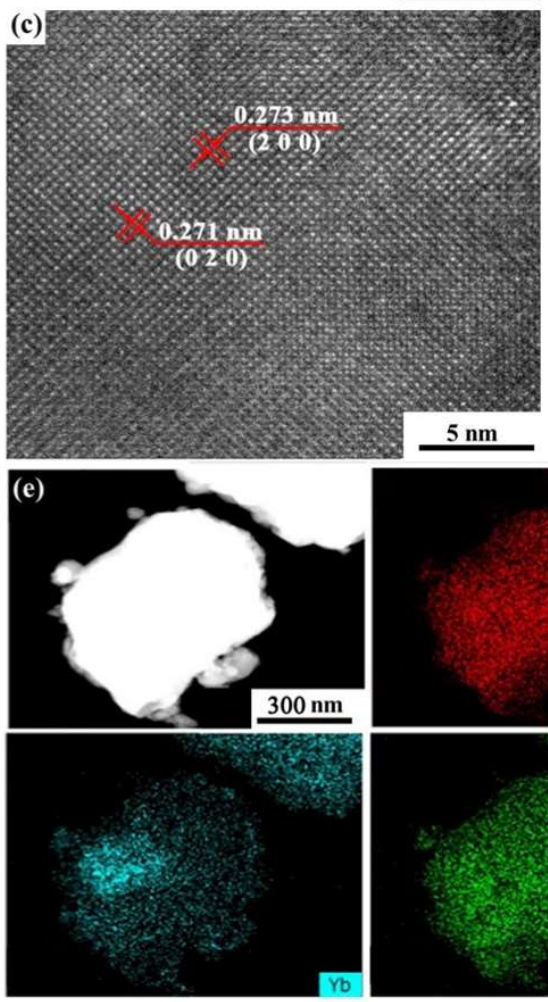
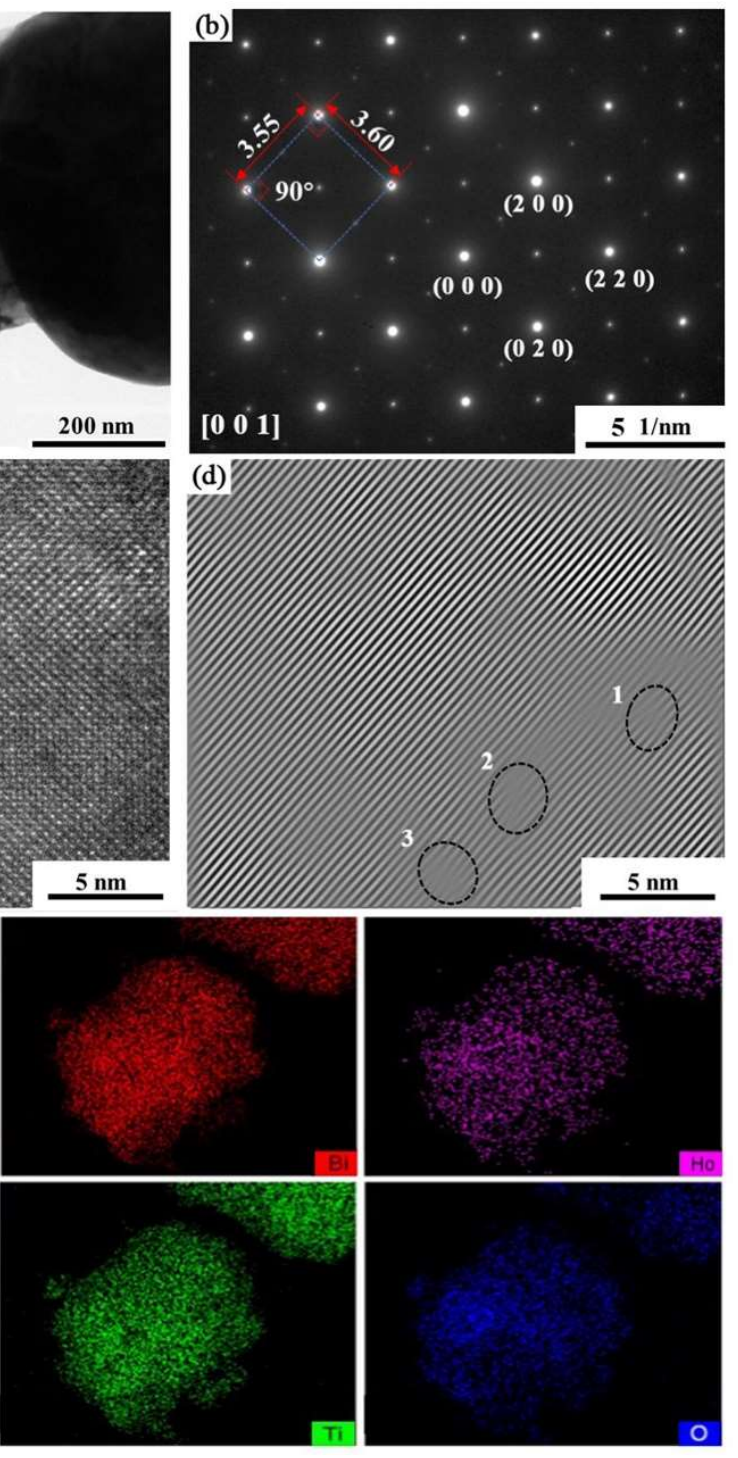

Figure 3. (a) TEM image, (b) SAED pattern, (c) HRTEM image, (d) fringes of (200) obtained by filtering, and (e) HAADF-STEM diagram and elemental distribution for BHYTO: 0.05Li samples.

Figure 4a shows a full scan of XPS in the range of 0 to $1000 \mathrm{eV}$ to analyze the chemical compositions and electron binding energy of BHYTO: $0.05 \mathrm{Li}$ samples, and as a comparison, XPS of pristine BHYTO samples was also shown to illustrate $\mathrm{Li}^{+}$doping effects. All the elements of $\mathrm{Bi}, \mathrm{Ti}, \mathrm{O}, \mathrm{Ho}, \mathrm{Yb}$, and $\mathrm{Li}$ in the phosphors were detected though the peak of $\mathrm{Li}^{+}$is very weak (see Figure A1 in Appendix A). Figure 4b shows high revolution XPS of $\mathrm{Bi} 4 \mathrm{f}$, and there are two main peaks centered at $158.3 \mathrm{eV}$ and $163.6 \mathrm{eV}$, very close to those of $\mathrm{Bi} 4 \mathrm{f}$ in $\mathrm{Bi}_{2} \mathrm{O}_{3}$ and $\mathrm{BTO}$, corresponding to a pair of spin-orbit splitting energy of $\mathrm{Bi} 4 \mathrm{f}_{7 / 2}$ and $\mathrm{Bi} 4 \mathrm{f}_{5 / 2}$ [29]. Additionally, there is the other pair of smaller peaks with higher energy on the right, and both of the energy difference between these two pairs of peaks are equal to $5.3 \mathrm{eV}$, implying that they are both originated from electron transition of 
$\mathrm{Bi} 4 \mathrm{f}$ orbit. During high-temperature heat treatment process to produce $\mathrm{Bi}_{4} \mathrm{Ti}_{3} \mathrm{O}_{12}$ based materials, oxygen vacancies were easily formed on the surface of the samples, which created a crystal field environment around $\mathrm{Bi}^{3+}$ ions different from that of $\mathrm{Bi}^{3+}$ ions internal the body. In this work, $\mathrm{Bi}_{S}$ ff and $\mathrm{Bi}_{C}$ ff denote as $\mathrm{Bi}^{3+}$ ions near the surface and internal crystal lattice, respectively, and $\mathrm{Bi}_{S} 4 \mathrm{f}$ has a higher binding energy than $\mathrm{Bi}_{\mathrm{C}} 4 \mathrm{f}$. For BHYTO: 0.05Li phosphors, the peaks of $\mathrm{Bi}_{S} 4 \mathrm{f}$ shifted close to $\mathrm{Bi}_{\mathrm{C}} 4 \mathrm{f}$ peaks and the area surrounded by $\mathrm{Bi}_{\mathrm{S}} 4 \mathrm{f}$ curve and based line became smaller, which suggests $\mathrm{Li}^{+}$doping had an effect on stabilizing oxygen in crystal lattice to make the environment around $\mathrm{Bi}^{3+}$ ions near the surface more similar to that in the body. As shown in Figure $4 \mathrm{c}$, the peaks of $457.6 \mathrm{eV}$ and $463.3 \mathrm{eV}$ correspond to the characteristic binding energy of $\mathrm{Ti} 2 \mathrm{p}_{3 / 2}$ and $\mathrm{Ti} 2 \mathrm{p}_{1 / 2}$ [30], and the peak of $\mathrm{Ti} 2 \mathrm{p}_{1 / 2}$ overlaps with $\mathrm{Bi} 4 \mathrm{~d}_{1 / 2}$ to form a wide energy peak. Note that nearly no change for the Ti $2 \mathrm{p}$ spectra indicates that $\mathrm{Li}^{+}$did not substitute $\mathrm{Ti}^{4+}$ for the perovskite layer in BTO host. Figure 4d shows two symmetrical peaks at $529.1 \mathrm{eV}$ and $530.9 \mathrm{eV}$, corresponding to the binding energy of $\mathrm{O} 1 \mathrm{~s}$ [31]. They were denoted as lattice oxygen $\left(\mathrm{O}_{\mathrm{L}}\right)$ and absorbed oxygen $\left(\mathrm{O}_{\mathrm{A}}\right)$, respectively, and can be usually used as the probe for material oxygen vacancies. Compared to the XPS of BHYTO samples [22], O 1s peaks for BHYTO: 0.05Li sample have the same positions, but have a wider full width at half maximum (FWHM) and larger integrated curve area surrounded by XPS fitting curve and based line, suggesting that $\mathrm{Li}^{+}$doping can stabilize oxygen in crystal lattice. This result is consistent with the previous analysis about $\mathrm{Bi} 4 \mathrm{f}$ spectra because of existing interaction between $\mathrm{Bi}$ and $\mathrm{O}$ elements. The XPS of $\mathrm{Yb} 4 \mathrm{~d}$ and Ho $3 \mathrm{p}$ are shown in Figure 4e, $\mathrm{f}$, where the values of FWHM and integrated curve area increased with $\mathrm{Li}^{+}$doping for the same reason as $\mathrm{Bi}^{3+} 4 \mathrm{f}$ orbits, and Ho $3 p$ peak shifted towards higher binding energy due to the charge repulsion effect of $\mathrm{Li}^{+}$to the electrons in $\mathrm{Ho} 3 \mathrm{p}$ orbits. The reduced oxygen vacancies are consistent with the improvement of crystallinity for $\mathrm{Li}^{+}$doped BHYTO phosphors. The results of XPS prove that the UC luminescence enhancement of BHYTO: $x$ Li phosphors is not caused from increased oxygen vacancies.

Figure 5a shows the UC emission spectra of BHYTO: $x$ Li phosphors under the excitation of $980 \mathrm{~nm}$ laser, there are three UC emission bands including a green band centered at $545 \mathrm{~nm}$, a red one centered at $658 \mathrm{~nm}$, and a near-infrared one at $756 \mathrm{~nm}$ for all the BHYTO: $x$ Li phosphors. According to energy level analysis, these emission bands are assigned to the characteristic transitions of ${ }^{5} \mathrm{~F}_{4} /{ }^{5} \mathrm{~S}_{2} \rightarrow{ }^{5} \mathrm{I}_{8},{ }^{5} \mathrm{~F}_{5} \rightarrow{ }^{5} \mathrm{I}_{8}$, and ${ }^{5} \mathrm{~F}_{4} /{ }^{5} \mathrm{~S}_{2} \rightarrow{ }^{5} \mathrm{I}_{7}$ of $\mathrm{Ho}^{3+}$, respectively [32,33]. With the increase in $\mathrm{Li}^{+}$content in BHYTO: $x \mathrm{Li}$ phosphors, the emission intensity increased gradually and reached an optimal value in BHYTO: 0.05 Li samples, which is about 2.2 times stronger than that of pristine BHYTO samples. However, the luminescence intensity decreased gradually with $\mathrm{Li}^{+}$further doping though they are much stronger than that of BHYTO and BHYTO: 0.02Li samples. Figure 5b shows the decay time of carriers for the BHYTO: $x$ Li phosphors monitored the dominant green emission $(545 \mathrm{~nm})$. Each curve in the graph represents the decay process with time for the carriers populated on Ho: ${ }^{5} \mathrm{~F}_{4} /{ }^{5} \mathrm{~S}_{2}$ level. The decay data were well fitted by Equation (1) [34] with bi-exponent items,

$$
I_{t}=I_{0}+\mathrm{A}_{1} e^{\frac{-t}{\tau_{1}}}+\mathrm{A}_{2} e^{\frac{-t}{\tau_{2}}}
$$

where, $I_{t}$ denotes luminescence intensity at decay time $t$, and $I_{0}$ denotes luminescence intensity at beginning decay time, $\mathrm{A}_{f}$ and $\mathrm{A}_{s}$ are constants, and $\tau_{f}$ and $\tau_{s}$ represent two different decay lifetime for the bi-exponent items. Mean lifetime $\left(\tau_{\mathrm{m}}\right)$ was expressed as Equation (2) [35].

$$
\tau_{m}=\int_{t_{0}}^{\infty} \frac{I(t)}{I_{0}} d t
$$



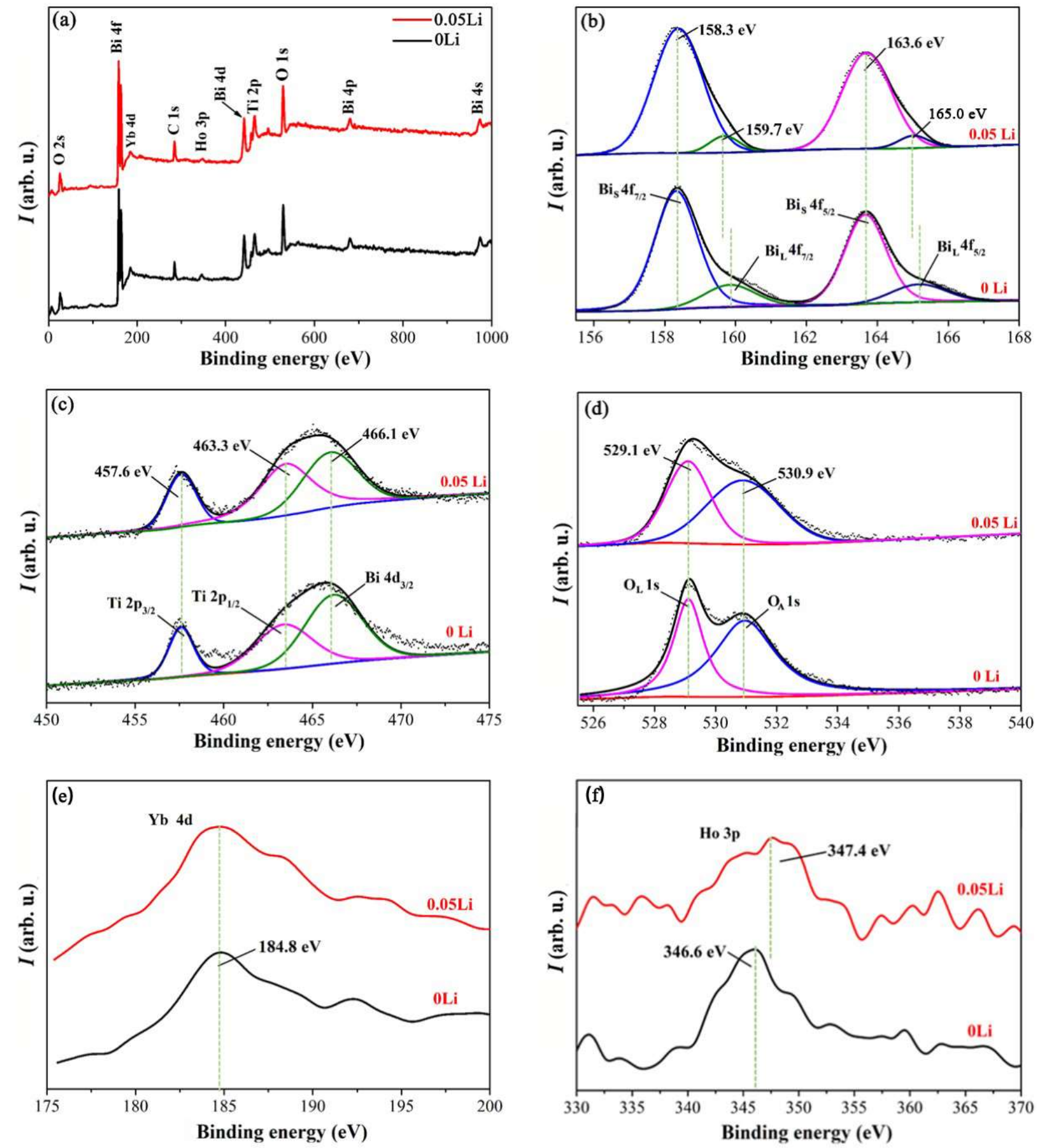

Figure 4. (a) XPS survey scan spectrum of pristine BHYTO and BHYTO: 0.05Li samples, and high resolution XPS spectra of (b) Bi 4f, (c) Ti 2p and Bi 4d, (d) O 1s, (e) Yb 4d, and (f) Ho 3p. 

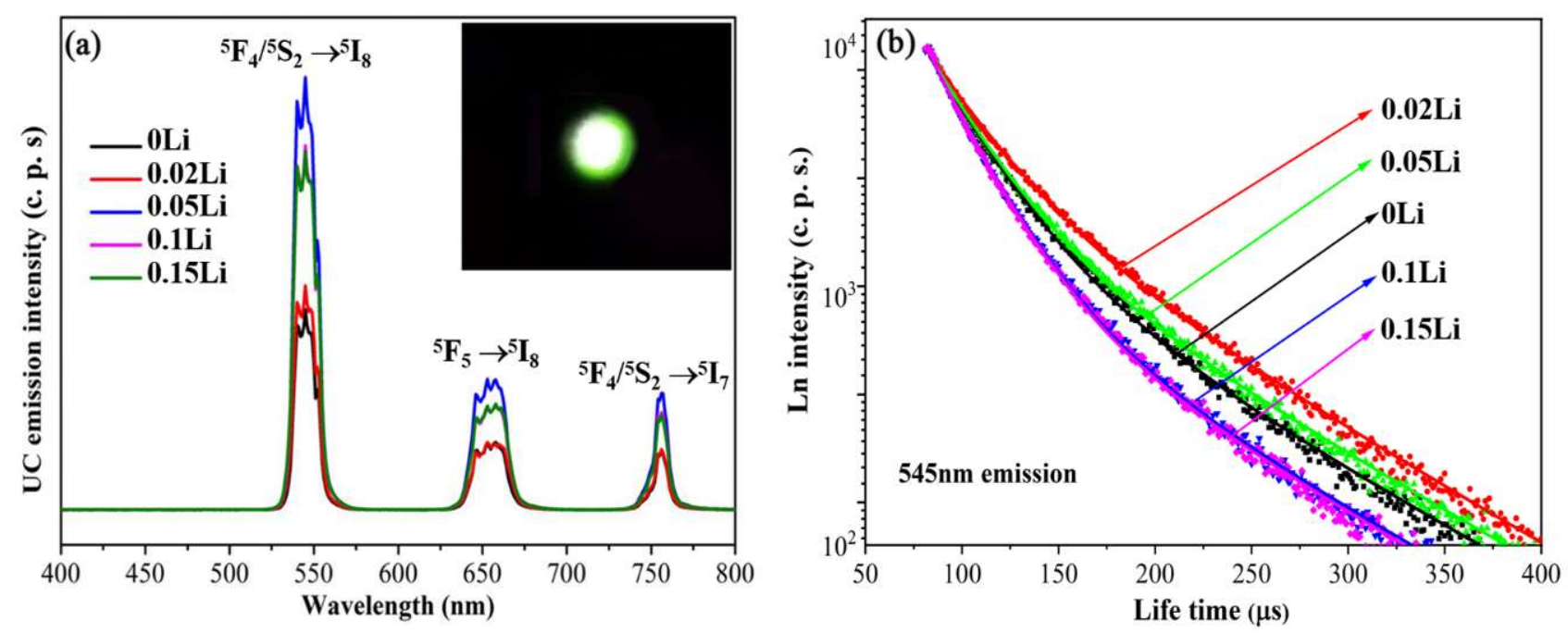

Figure 5. (a) UC PLS pumped by a $980 \mathrm{~nm}$ laser and the pumping power and its density were set to be $245 \mathrm{~mW}$ and $613 \mathrm{~mW} / \mathrm{cm}^{2}$, respectively (b) decay time of carriers on ${ }^{5} \mathrm{~F}_{4} /{ }^{5} \mathrm{~S}_{2}$ level of $\mathrm{Ho}^{3+}$ for BHYTO: $x \operatorname{Li}(x=0,0.02,0.05,0.10,0.15)$ phosphors monitored at $545 \mathrm{~nm}$ emission.

Based on the data in Figure $5 \mathrm{~b}$ and Equation (2), the mean lifetime of Ho: ${ }^{5} \mathrm{~F}_{4} /{ }^{5} \mathrm{~S}_{2}$ was calculated to be $55.28 \mu \mathrm{s}, 65.99 \mu \mathrm{s}, 57.51 \mu \mathrm{s}, 46.22 \mu \mathrm{s}$ and $45.25 \mu \mathrm{s}$ for BHYTO: $x \mathrm{Li}$ samples with $x$ equal to $0,0.02,0.05,0.10$, and 0.15 , respectively. Compared to BHYTO: 0.02Li samples, the lifetime of BHYTO: $x \operatorname{Li}(x=0.05,0.10,0.15)$ is shorter while the UC emission intensity is stronger.

As is well known, many factors might have effects on the emission efficiency of $\mathrm{RE}^{3+}$. In this article, the effects of charge compensation should be excluded because that charge compensation was used to apply in a charge imbalanced system, such as $\mathrm{CaSrAl}_{2} \mathrm{SiO}_{7}$ : $\mathrm{Ce}^{3+}$ with the substitution of bivalent $\mathrm{Sr}^{2+}$ by trivalent $\mathrm{Ce}^{3+}[36], \mathrm{Ca}_{3}\left(\mathrm{PO}_{4}\right)_{2}: \mathrm{Tb}^{3+}$ with the substitution of bivalent $\mathrm{Ca}^{2+}$ by trivalent $\mathrm{Tb}^{3+}$ [17], and $\mathrm{ZnO}$ : $\mathrm{Eu}^{3+}$ with the substitution of bivalent $\mathrm{Zn}^{2+}$ by trivalent $\mathrm{Eu}^{3+}$ [37]. Codoping monovalent alkali element such as $\mathrm{Li}^{+}, \mathrm{Na}^{+}$, and $\mathrm{K}^{+}$with the trivalent $\mathrm{RE}^{3+}$ can realize charge compensation. However, the situation is distinctly different. For the $\mathrm{Bi}_{3.46} \mathrm{Ho}_{0.04} \mathrm{Yb}_{0.5} \mathrm{Ti}_{3} \mathrm{O}_{12}$ samples without $\mathrm{Li}^{+}$ doping, it is a charge balanced system, and charge compensation is not necessary and the substitution of $\mathrm{Bi}^{3+}$ by $\mathrm{Li}^{+}$can even lead to the imbalance of charge in the whole sample. So the luminescence enhancement by $\mathrm{Li}^{+}$in this work seems not to be relevant with charge compensation. There is no obvious difference in particle size was observed for the samples with various $\mathrm{Li}^{+}$contents. The results of SEM and Zeta potential suggest that the change of UC luminescence for BHYTO: $x \mathrm{Li}$ phosphors with different $\mathrm{Li}^{+}$contents is not originated from particle size. The luminescence enhancement through $\mathrm{Li}^{+}$doping in this study is also not caused by crystal distortion or increased strain. In order to further prove this viewpoint, $\mathrm{Eu}^{3+}$ doped BTO: $x \mathrm{Li}$ (BETO: $x \mathrm{Li}$ ) samples were also fabricated in the same method as BHYTO: $x \mathrm{Li}$ phosphors. The PLS of $\mathrm{Bi}_{3.6} \mathrm{Eu}_{0.4} \mathrm{Ti}_{3} \mathrm{O}_{12}: x \mathrm{Li}$ (BETO: $x \mathrm{Li}, x=0,0.05,0.1,0.15$ ) are shown in Figure A2a (in Appendix A) since $\mathrm{Eu}^{3+}$ is a famous luminescent probe to examine structural symmetry around a certain ion in lattice based on the ratio of emission intensity of ${ }^{5} \mathrm{D}_{0} \rightarrow{ }^{7} \mathrm{~F}_{2}$ (electric-dipole-allowed transition) to ${ }^{5} \mathrm{D}_{0} \rightarrow{ }^{7} \mathrm{~F}_{1}$ (magnetic-dipole-allowed one) of $\mathrm{Eu}^{3+}$ [16]. $\mathrm{Eu}^{3+}$ can be used as luminescent probe for BHYTO: $x \mathrm{Li}$ phosphors because it can substitute the same $\mathrm{Bi}^{3+}$ sites as $\mathrm{Ho}^{3+}, \mathrm{Yb}^{3+}$, and $\mathrm{Li}^{+}$in BTO lattice through above XRD analysis. There are two strong red emission bands positioned at about $615 \mathrm{~nm}$ and $594 \mathrm{~nm}$ in PLS of BETO: $x$ Li samples, corresponding to ${ }^{5} \mathrm{D}_{0} \rightarrow{ }^{7} \mathrm{~F}_{2}$ and ${ }^{5} \mathrm{D}_{0} \rightarrow{ }^{7} \mathrm{~F}_{1}$ transitions of $\mathrm{Eu}^{3+}$, respectively. As shown in Figure A2b (in Appendix A), the ratios decreased with the increase in $\mathrm{Li}^{+}$doping content $(0 \leq x \leq 0.15)$ in the BETO: $x \mathrm{Li}$ samples. This result reflected an increased structural symmetry and a decreased crystal distortion with the increase in $\mathrm{Li}^{+}$content in the phosphors. Obviously, the luminescence enhancement was not originated from crystal distortion for BHYTO: $x \mathrm{Li}$ and BETO: $x \mathrm{Li}$ phosphors. For 
BHYTO: $x$ Li phosphors, XRD results showed that the increase in $\mathrm{Li}^{+}$doping content led to the gradual increase in grain size and promoted the improvement of crystallinity. XPS results showed that the oxygen vacancy defects gradually decrease and $\mathrm{Li}^{+}$can act as a flux, which further confirmed that $\mathrm{Li}^{+}$doping would improve the crystallinity of the sample. Furthermore, improved crystallinity of $\mathrm{Li}^{+}$doped samples can increase oscillating strength for optical transitions, reduce quenching centers, such as density of grain boundary and oxygen vacancies [38], which is a main positive factor to improve emissions of RE phosphors. However, the UC luminescence is not only determined by crystallization since excessive $\mathrm{Li}^{+}$doping $(x \geq 0.10)$ can make some $\mathrm{RE}$ ions squeezed out or deviated from their original sites in BHYTO lattice, leading to increased aggregation of RE ions, so, thus, decreasing the dispersibility of RE ions to produce local concentration quenching, so thus resulting in a weak degradation of UC emission intensity for BHYTO: $x$ Li phosphors $(x \geq 0.10)$.

For a UC luminescent process, integral emission intensity $(I)$ is usually proportional to the power $(n)$ of pumping laser power $(P)$, and the relationship formula is shown as Equation (3) [39],

$$
I=P^{n}
$$

where index $n$ denoted the number of absorbed photons in the UC process. Figure $6 \mathrm{a}, \mathrm{b}$ show the dependence of UC intensities of green, red and near-infrared emissions on pumping power of $980 \mathrm{~nm}$ laser for BHYTO and BHYTO: 0.05Li samples, and the monitored emission wavelengths are $545 \mathrm{~nm}, 658 \mathrm{~nm}$, and $756 \mathrm{~nm}$, respectively. There appeared good linear fitting relationships between UC emission intensity and pumping power for all the emissions of each sample. The fitting index $R^{2}$ values for each emission are all above 0.996 for BHYTO samples and above 0.992 for BHYTO: 0.05Li ones. The measured slope value is indicative of an upconversion process, which involves at least $n$ photons, where $n$ is the smallest integer greater than slope value (or equal to slope value if slope value is an integer) [40]. The slope values of all fitting lines are from 1.19 to 1.42, which lie in the range of 1 to 2, proving that the UC mechanism for BHYTO: $x$ Li phosphors belong to a double-photon process for each of green, red and near-infrared emissions. The slope values of the fitting line deviate from the up limit of 2 and approaches close to the low limit value of 1 . The deviation is caused from the competition between linear decay and UC processes for the depletion of the intermediate excited states. For a typical upconversion process mainly composed of three levels, if linear decay of the intermediate level is the dominant depletion, upconversion can be neglected, and, consequently, excited-state population densities $\left(N_{2}\right)$ in emission level has a relationship with excited-state population densities $\left(N_{1}\right)$ in intermediate level and pumping power $(P): N_{2} \propto N_{1}^{2} \propto P^{2}$, corresponding to up limit of 2. In contrast, if upconversion is dominant, the linear decay term can be neglected, resulting in: $N_{2} \propto N_{1}{ }^{2} \propto P$, corresponding to the lower limit of 1 [41]. The slope values are closer to the low limit, suggesting that upconversion is more obvious than decay for the depletion of the intermediate level. From another point of view, the low slop values reflect that BHYTO: $x$ Li phosphors have relatively high upconversion efficiency. The phenomenon of low $n$ value for double-photon upconversion process also occurs in $\mathrm{Yb}^{3+}-\mathrm{Er}^{3+}$ doped $\mathrm{BaTiO}_{3}$ and $\mathrm{Ho}^{3+} / \mathrm{Er}^{3+}-\mathrm{Yb}^{3+}$ co-doped NaLaMgWO 6 [42,43]. 

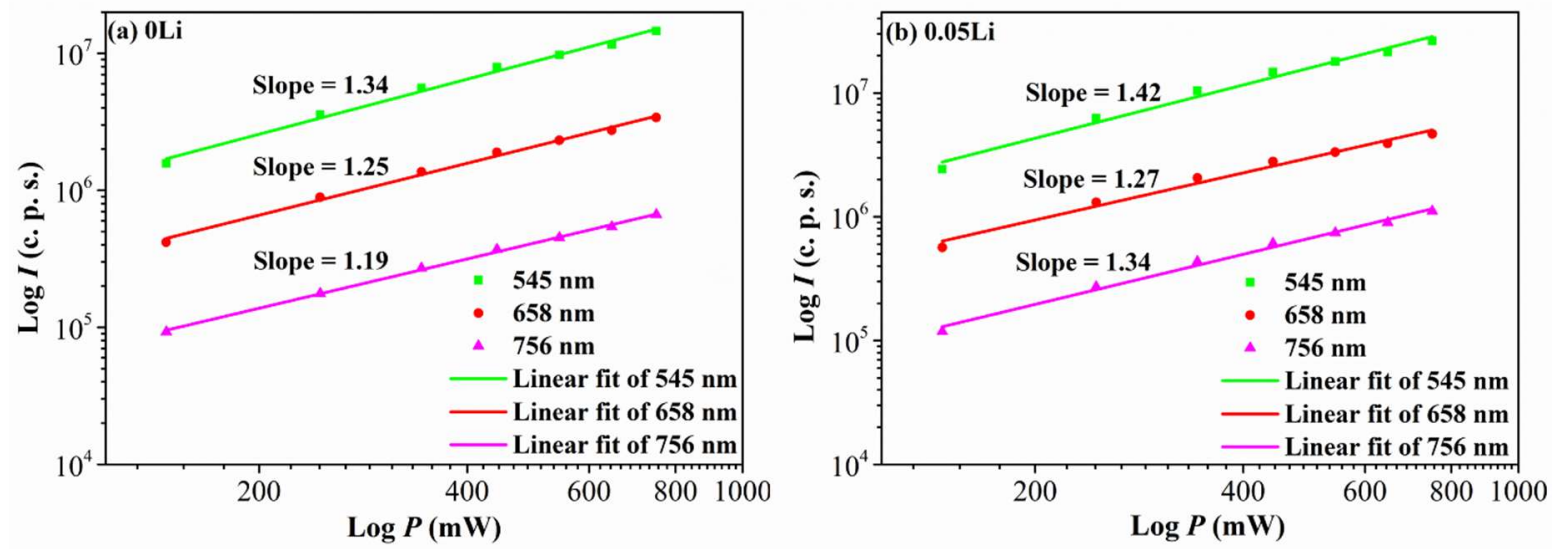

Figure 6. Log-log diagram of the dependence of UC emission intensities for green, red and near-infrared emissions on pumping power $(P)$ of $980 \mathrm{~nm}$ excitation for (a) BHYTO and (b) BHYTO: 0.05Li samples.

The energy transfer process for the UC luminescence of BHYTO: $x \operatorname{Li}(x=0,0.02,0.05$, $0.10,0.15$ ) is shown in the Figure 7. Under $980 \mathrm{~nm}$ excitation, some $\mathrm{Yb}^{3+}$ ions absorbed the first photon energy and were pumped to exciting state from ground state (i.e., $\mathrm{Yb}$ : ${ }^{2} \mathrm{~F}_{7 / 2}+\mathrm{h} v_{0} \rightarrow \mathrm{Yb}:{ }^{2} \mathrm{~F}_{5 / 2}$ ), then transferred the energy to neighboring $\mathrm{Ho}^{3+}$ ions and excited them to intermediate ${ }^{5} \mathrm{I}_{6}$ level (i.e., $\mathrm{Yb}:{ }^{2} \mathrm{~F}_{5 / 2}+\mathrm{Ho}:{ }^{5} \mathrm{I}_{8} \rightarrow \mathrm{Yb}:{ }^{2} \mathrm{~F}_{7 / 2}+\mathrm{Ho}:{ }^{5} \mathrm{I}_{6}$ ). Some $\mathrm{Ho}^{3+}$ ions populated in this level absorb the second photon energy transferred from $\mathrm{Yb}^{3+}$ and pumped to ${ }^{5} \mathrm{~F}_{4} /{ }^{5} \mathrm{~S}_{2}$ levels (i.e., $\mathrm{Yb}:{ }^{2} \mathrm{~F}_{5 / 2}+$ Ho: ${ }^{5} \mathrm{I}_{6} \rightarrow \mathrm{Yb}:{ }^{2} \mathrm{~F}_{7 / 2}+$ Ho: ${ }^{5} \mathrm{~F}_{4} /{ }^{5} \mathrm{~S}_{2}$ ). When these $\mathrm{Ho}^{3+}$ ions in ${ }^{5} \mathrm{~F}_{4} /{ }^{5} \mathrm{~S}_{2}$ transited to ${ }^{5} \mathrm{I}_{7}$ and ${ }^{5} \mathrm{I}_{8}$, a near-infrared emission centered at $756 \mathrm{~nm}$ and a green emission centered at $545 \mathrm{~nm}$ were produced (i.e., Ho: ${ }^{5} \mathrm{~F}_{4} /{ }^{5} \mathrm{~S}_{2} \rightarrow \mathrm{Ho}:{ }^{5} \mathrm{I}_{7}+\mathrm{h} v_{1}$, Ho: ${ }^{5} \mathrm{~F}_{4} /{ }^{5} \mathrm{~S}_{2} \rightarrow$ Ho: ${ }^{5} \mathrm{I}_{8}+\mathrm{h} \mathrm{v}_{2}$ ), respectively. Some $\mathrm{Ho}^{3+}$ populated in ${ }^{5} \mathrm{I}_{6}$ level decayed to the next ${ }^{5} \mathrm{I}_{7}$ level through non-radiative relaxation, and then absorbed the second photon energy and pumped to ${ }^{5} \mathrm{~F}_{5}$ emission level (i.e., $\mathrm{Yb}:{ }^{2} \mathrm{~F}_{5 / 2}+\mathrm{Ho}:{ }^{5} \mathrm{I}_{7} \rightarrow \mathrm{Yb}:{ }^{2} \mathrm{~F}_{7 / 2}+$ Ho: ${ }^{5} \mathrm{~F}_{5}$ ), finally producing a $658 \mathrm{~nm}$ red emission when they came back to ground level directly (i.e., Ho: ${ }^{5} \mathrm{~F}_{5} \rightarrow \mathrm{Ho}:{ }^{5} \mathrm{I}_{8}+\mathrm{h} v_{3}$ ). The above emission process is a typical ET (energy transfer) process from $\mathrm{Yb}^{3+}$ to $\mathrm{Ho}^{3+}$. Which existed other energy transfer processes to produce the above emissions, such as GAT (energy transfer through absorption energy by ground state) [44] or EAT (excitation state absorption) [45], but ET process was mainly responsible for the energy transfer in $\mathrm{Ho}^{3+}-\mathrm{Yb}^{3+}$ co-doped phosphors because $\mathrm{Yb}^{3+}$ has much larger absorption section than $\mathrm{Ho}^{3+}$ for $980 \mathrm{~nm}$ exciting light. It is well agreement with the fact that the UC emission intensity is relatively weak for $\mathrm{Ho}^{3+}$ single-doped BTO phosphors [9].

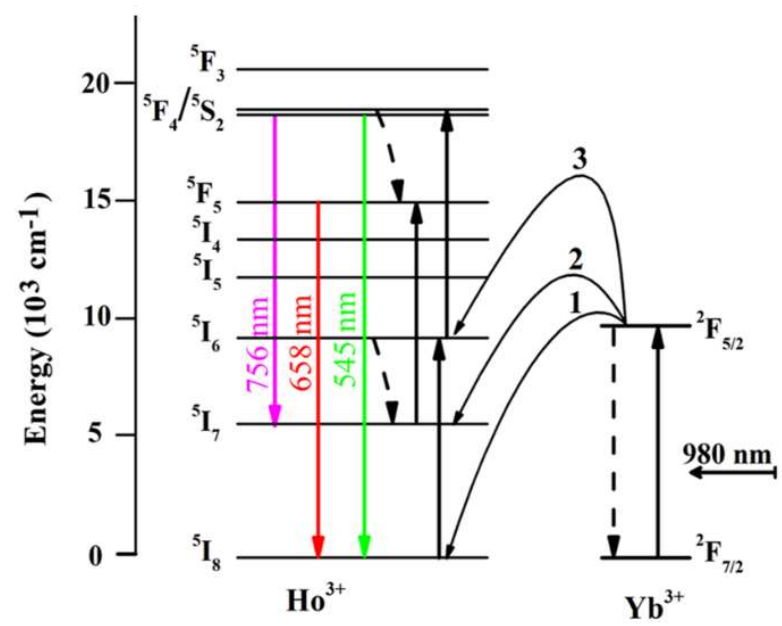

Figure 7. Schematic diagram of energy transfers during the UC process for BHYTO: $x$ Li phosphors. 


\section{Conclusions}

In this study, a series of novel efficient $\mathrm{Li}^{+}$doped BHYTO phosphors were fabricated successfully. The detected $\mathrm{Li}^{+}$content $\left(C_{\mathrm{D}}\right)$ is very close to the nominal doped one $\left(C_{\mathrm{N}}\right)$ in the samples BHYTO: $x \mathrm{Li}$ samples with $x \geq 0.05$ through ICPMS measurement. $\mathrm{Li}^{+}$entered into the interspace of BHYTO crystal lattice when its dosage was low, and substitute $\mathrm{Bi}^{3+}$ sites with further increase in $\mathrm{Li}^{+}$dosage. The crystallinity and grain sizes increase monotonously with the increase in $\mathrm{Li}^{+}$content in BHYTO: $x \mathrm{Li}$ samples. Compared to BHYTO samples, the UC emission intensity of BHYTO: $x$ Li increased obviously when $x \geq 0.05$. UC emission mechanism of the BHYTO: $x$ Li phosphors belong to a doublephoton energy transfer process mainly through ET from $\mathrm{Yb}^{3+}$ to $\mathrm{Ho}^{3+}$ without $\mathrm{Li}^{+}$direct participation. The causes of luminescence enhancement were discussed in details based on the results of XRD, SEM, TEM, EDS, XPS, and PLS measurements of Eu ${ }^{3+}$ doped BETO: $x$ Li. The improved crystallization and reduced quenching centers such as oxygen vacancies promote light absorption from pumping source and increase oscillating strength for optical transitions, which have primary responsibility for the improved UC luminescence of BHYTO: $x$ Li phosphors. It can be inferred that the method of luminescence enhancement in this study can probably be extended for the other RE phosphors with similar structure.

Author Contributions: Performing the experiments, F.R.; Data collection and analysis, F.R.; Writing initial draft, F.R.; Data collection, J.Z.; Performing the experiments, D.W.; Performing the experiments, X.W.; Data collection, X.W.; Conceptualization, F.G; Methodology, F.G.; Resources, F.G.; Supervision, F.G.; Validation, F.G.; Review and Revised manuscript, F.G.; Acquisition of the financial support for the project, F.G. All authors have read and agreed to the published version of the manuscript.

Funding: This research was funded by the Programs for Natural Science Foundation of Guangxi (2019GXNSFAA185013), Science and Technology Major Project of Guangxi Province (AA18118030), and Guangxi Key Laboratory Development Foundation (GXYSSF1802).

Data Availability Statement: All data generated or analyzed during this study are included in this published article.

Acknowledgments: The authors thank financial support from the Programs for Natural Science Foundation of Guangxi (2019GXNSFAA185013), Science and Technology Major Project of Guangxi Province (AA18118030), and Guangxi Key Laboratory Development Foundation (GXYSSF1802).

Conflicts of Interest: The authors declare no competing interests.

\section{Appendix A}

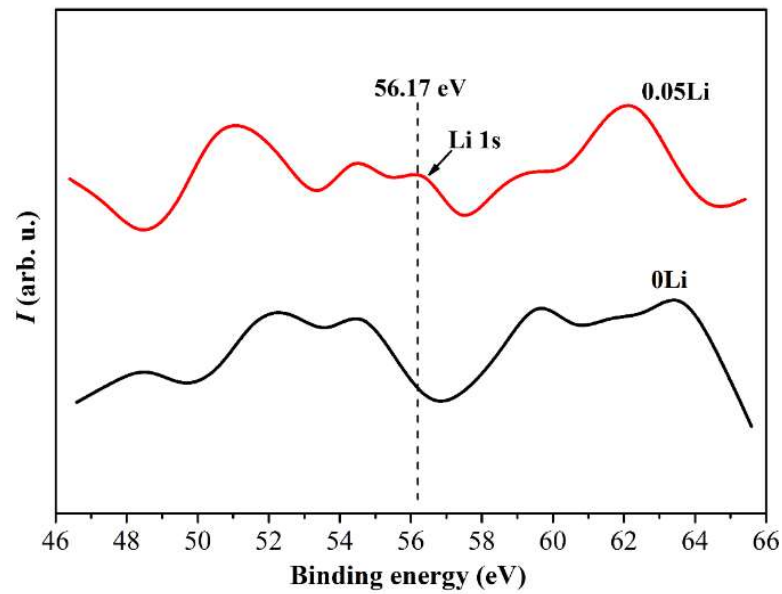

Figure A1. High resolution XPS spectra of Li 1s. 

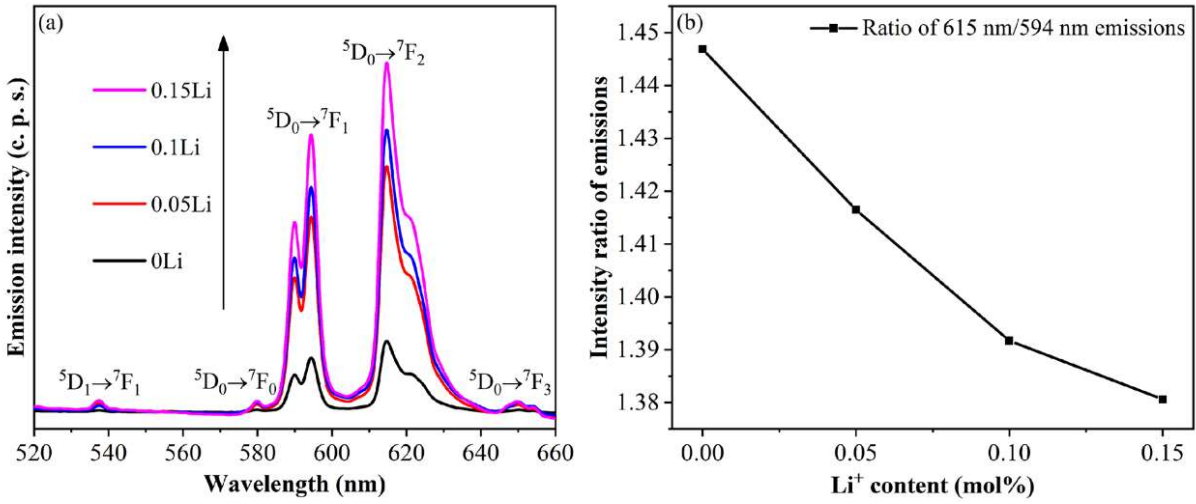

Figure A2. (a) The PLS and (b) the ratios of $615 \mathrm{~nm} / 594 \mathrm{~nm}$ emission for $\mathrm{Bi}_{3.6} \mathrm{Eu}_{0.4} \mathrm{Ti}_{3} \mathrm{O}_{12}: x \mathrm{Li}(\mathrm{BETO}$ : $x \operatorname{Li}, x=0,0.05,0.1,0.15)$.

\section{References}

1. Meng, Z.; Zhang, S.; Wu, S. Power density dependent upconversion properties of $\mathrm{NaYbF}_{4}: \mathrm{Er}^{3+} @ \mathrm{NaYbF}_{4}: \mathrm{Tm}^{3+} @ \mathrm{NaYF}_{4}$ nanoparticles and their application in white-light emission LED. J. Lumin. 2020, 227, 117566. [CrossRef]

2. Shin, J.; Kyhm, J.H.; Hong, A.R.; Song, J.D.; Lee, K.; Ko, H.; Jang, H.S. Multicolor tunable upconversion luminescence from sensitized seed-mediated grown $\mathrm{LiGdF}_{4}: \mathrm{Yb}$, Tm-based core/triple-shell nanophosphors for transparent displays. Chem. Mater. 2018, 30, 8457-8464. [CrossRef]

3. Lim, C.; Aleksandrovsky, A.; Atuchin, V.; Molokeev, M.; Oreshonkov, A. Microwave-employed sol-gel synthesis of scheelite-type microcrystalline $\mathrm{AgGd}\left(\mathrm{MoO}_{4}\right)_{2}: \mathrm{Yb}^{3+} / \mathrm{Ho}^{3+}$ upconversion yellow phosphors and their spectroscopic properties. Crystals 2020, 10,1000 .

4. Tang, Z.; Han, W.; Huang, Z.; Qi, J.; Zhang, Y.; Yi, J.; Yuan, J.; Lu, T. Near-infrared luminescent properties of Ln: LaGdZr ${ }_{2} \mathrm{O}_{7}$ $(\mathrm{Ln}=\mathrm{Nd}, \mathrm{Yb})$ transparent ceramics for solid-state laser applications. Ceram. Int. 2020, 46, 22270-22275. [CrossRef]

5. Oppo, C.I.; Corpino, R.; Ricci, P.C.; Paul, M.C.; Das, S.; Pal, M.; Bhadra, S.K.; Yoo, S.; Kalita, M.P.; Boyland, A.J.; et al. Incorporation of $\mathrm{Yb}^{3+}$ ions in multicomponent phase-separated fibre glass preforms. Opt. Mater. 2011, 34, 660-664. [CrossRef]

6. Badge, S.K.; Deshpande, A.V. Study of dielectric and ferroelectric properties of bismuth titanate $\left(\mathrm{Bi}_{4} \mathrm{Ti}_{3} \mathrm{O}_{12}\right)$ ceramic prepared by sol-gel synthesis and solid state reaction method with varying sintering temperature. Solid. State. Ion. 2019, 334, 21-28. [CrossRef]

7. Xie, X.; Wang, T.; Zhou, Z.; Cheng, G.; Liang, R.; Dong, X. Enhanced piezoelectric properties and temperature stability of $\mathrm{Bi}_{4} \mathrm{Ti}_{3} \mathrm{O}_{12}$-based Aurivillius ceramics via W./Nb substitution. J. Eur. Ceram. Soc. 2019, 39, 957-962. [CrossRef]

8. Yang, Z.; Yan, L.; Yan, D.; Song, Z.; Zhou, D.; Yin, Z.; Qiu, J.; Chen, G. Color tunable upconversion emission in Yb, Er co-doped bismuth titanate inverse opal. J. Am. Ceram. Soc. 2011, 94, 2308-2310. [CrossRef]

9. Gao, F.; Liu, H.F.; Ren, F.; Wang, K.T.; Li, X.S.; Wang, Y.B.; He, C.; Wei, Y.Z. Tunable structure and intensive upconversion photoluminescence for $\mathrm{Ho}^{3+}-\mathrm{Yb}^{3+}$ codoped bismuth titanate composite synthesized by sol-gel-combustion (SGC) method. Ceram. Int. 2019, 46, 3015-3022. [CrossRef]

10. Gao, F.; Zhou, H.; Wu, G.H.; Qin, N.; Bao, D.H. Combination of strong blue up-conversion photoluminescence and greatly enhanced ferroelectric polarization in $\mathrm{Tm}^{3+}-\mathrm{Yb}^{3+}-\mathrm{W}^{6+}-$ doped $\mathrm{Bi}_{4} \mathrm{Ti}_{3} \mathrm{O}_{12}$ thin films. J. Electrochem. Soc. 2011, 158, G128-G131. [CrossRef]

11. Huang, H.; Liang, X.; Wang, Z.; Wang, P.; Zheng, Z.; Liu, Y.; Zhang, X.; Qin, X.; Dai, Y.; Huang, B. Bi ${ }_{20} \mathrm{TiO}_{32}$ nanoparticles doped with $\mathrm{Yb}^{3+}$ and $\mathrm{Er}^{3+}$ as UV, visible, and near-infrared responsive photocatalysts. ACS Appl. Nano Mater. 2019, 2, 5381-5388. [CrossRef]

12. Bokolia, R.; Mondal, M.; Rai, V.K.; Sreenivas, K. Enhanced infrared-to-visible up-conversion emission and temperature sensitivity in $\left(\mathrm{Er}^{3+}, \mathrm{Yb}^{3+}\right.$, and $\left.\mathrm{W}^{6+}\right)$ tri-doped $\mathrm{Bi}_{4} \mathrm{Ti}_{3} \mathrm{O}_{12}$ ferroelectric oxide. J. Appl. Phys. 2017, 121, 084101. [CrossRef]

13. Xiang, G.; Liu, X.; Xia, Q.; Liu, X.; Xu, S.; Jiang, S.; Zhou, X.; Li, L.; Wu, D.; Ma, L.; et al. Design of a bi-functional NaScF 4 : $\mathrm{Yb}^{3+} / \mathrm{Er}^{3+}$ nanoparticles for deep-tissue bioimaging and optical thermometry through $\mathrm{Mn}^{2+}$ doping. Talanta 2021, $224,121832$. [CrossRef]

14. Chung, J.H.; Ryu, J.H.; Eun, J.W.; Lee, J.H.; Lee, S.Y.; Heo, T.H.; Shim, K.B. High enhancement of green upconversion luminescence of $\mathrm{Li}^{+} / \mathrm{Er}^{3+} / \mathrm{Yb}^{3+}$ tri-doped $\mathrm{CaMoO}_{4}$. Mater. Chem. Phys. 2012, 134, 695-699. [CrossRef]

15. Jia, Y.; Song, Y.; Bai, Y.; Wang, Y. Upconverted photoluminescence in $\mathrm{Ho}^{3+}$ and $\mathrm{Yb}^{3+}$ codoped $\mathrm{Gd}_{2} \mathrm{O}_{3}$ nanocrystals with and without $\mathrm{Li}^{+}$ions. Luminescence 2011, 26, 259-263. [CrossRef] [PubMed]

16. Yi, S.S.; Shim, K.S.; Yang, H.K.; Moon, B.K.; Choi, B.C.; Jeong, J.H.; Kim, J.H.; Bae, J.S. Improved cathodoluminescent characteristics of $\mathrm{Y}_{2} \mathrm{O}_{3}: \mathrm{Eu}^{3+}$ thin films by Li-doping. Appl. Phys. A 2007, 87, 667-671. [CrossRef]

17. Jung, G.W.; Park, K. Effect of monovalent charge compensators on the photoluminescence properties of $\mathrm{Ca}_{3}\left(\mathrm{PO}_{4}\right)_{2}: \mathrm{Tb}^{3+}, \mathrm{A}^{+}$ (A = Li, Na, K) phosphors. J. Mater. Sci. Technol. 2021, 82, 187-196. [CrossRef]

18. Mao, C.; Yang, X.; Zhao, L. Simultaneous morphology control and upconversion fluorescence enhancement of $\mathrm{NaYF}_{4}$ : $\mathrm{Yb}_{\mathrm{b}}$ Er crystals through alkali ions doping. Chem. Eng. J. 2013, 229, 429-435. [CrossRef] 
19. Jin, D.; Yang, J.; Miao, X.; Wang, L.; Guo, S.; Wang, N.; Wang, L. Highly enhanced photoluminescence of $\mathrm{YBO}_{3}: \mathrm{Eu}^{3+} \mathrm{micro}^{-\mathrm{spheres}}$ by co-adding Li ion and alkaline-earth metal ions. Mater. Lett. 2012, 79, 225-228. [CrossRef]

20. Gao, F.; Zhang, Q.; Ding, G.; Qin, N.; Bao, D. Strong upconversion photoluminescence and large ferroelectric polarization in $\mathrm{Er}^{3+}-\mathrm{Yb}^{3+}-\mathrm{W}^{6+}$ triply substituted bismuth titanate thin films prepared by chemical solution deposition. J. Am. Ceram. Soc. 2011, 94, 3867-3870. [CrossRef]

21. Dong, M.; Li, X.; Chi, F.; Wei, X.; Yin, M.; Chen, Y. Trivalent Yb/Ho/Ce tri-doped core/shell NaYF 4 nanoparticles for tunable upconversion luminescence from green to red. J. Rare. Earth 2017, 35, 629-636. [CrossRef]

22. Bordj, S.; Satha, H.; Barros, A.; Zambon, D.; Jouart, J.P.; Diaf, M.; Mahiou, R. Spectroscopic characterization by up conversion of $\mathrm{Ho}^{3+} / \mathrm{Yb}^{3+}$ codoped $\mathrm{CdF}_{2}$ single crystal. Opt. Mater. 2021, 118, 111249. [CrossRef]

23. Ramana, E.V.; Prasad, N.V.; Tobaldi, D.M.; Zavašnik, J.; Singh, M.K.; Hortigüela, M.J.; Seabra, M.P.; Prasad, G.; Valente, M.A. Effect of samarium and vanadium co-doping on structure, ferroelectric and photocatalytic properties of bismuth titanate. RSC. Adv. 2017, 7, 9680-9692. [CrossRef]

24. Lu, B.X.; Chen, K.; Wang, W.L.; Jiang, B.B. Effects of $\mathrm{Li}_{2} \mathrm{O}$ and $\mathrm{Na}_{2} \mathrm{O}$ on the crystallization behavior of lime-alumina-based mold flux for casting high-Al steels. Metall. Mater. Trans. B 2014, 4, 1496-1509. [CrossRef]

25. Oberžan, M.; Holc, J.; Buh, M.; Kuščer, D.; Lavrač, I.; Kosec, M. High-alumina porcelain with the addition of a Li 2 O-bearing fluxing agent. J. Eur. Ceram. Soc. 2009, 29, 2143-2152. [CrossRef]

26. Hedden, D.B.; Torardi, C.C.; Zegarski, W. $\mathrm{M}^{\prime}-\mathrm{RTaO}_{4}$ Synthesis: Activation of the precursor oxides by the reaction flux. J. Solid. State. Chem. 1995, 118, 419-421. [CrossRef]

27. Zhang, Y.; Chen, Z.; Lu, Z. A facile method for the preparation of colored $\mathrm{Bi}_{4} \mathrm{Ti}_{3} \mathrm{O}_{12-\mathrm{x}}$ nanosheets with enhanced visible-light photocatalytic hydrogen evolution activity. Nanomaterials 2018, 8, 261. [CrossRef]

28. Chen, Y.; Yang, B.; Zhou, Y.; Wu, Y.; Zhu, H. Evaluation of pitting corrosion in duplex stainless steel $\mathrm{Fe}_{20} \mathrm{Cr}_{9} \mathrm{Ni}_{\text {for nuclear }}$ power application. Acta. Mater. 2020, 197, 172-183. [CrossRef]

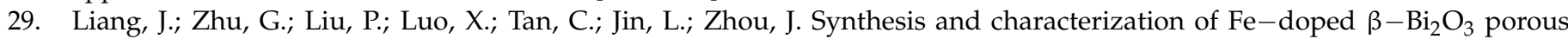
microspheres with enhanced visible light photocatalytic activity. Acta Mater. 2014, 72, 272-282. [CrossRef]

30. Chang, M.J.; Cui, W.N.; Liu, J.; Wang, K.; Du, H.L.; Qiu, L.; Fan, S.M.; Luo, Z.M. Construction of novel $\mathrm{TiO}_{2} / \mathrm{Bi}_{4} \mathrm{Ti}_{3} \mathrm{O}_{12} / \mathrm{MoS}_{2}$ core/shell nanofibers for enhanced visible light photocatalysis. J. Mater. Sci. Technol. 2020, 36, 97-105. [CrossRef]

31. Zhao, X.; Yang, H.; Cui, Z.; Wang, X.; Yi, Z. Growth process and CQDs-modified $\mathrm{Bi}_{4} \mathrm{Ti}_{3} \mathrm{O}_{12}$ square plates with enhanced photocatalytic performance. Micromachines 2019, 10, 66. [CrossRef]

32. Ragin, T.; Baranowska, A.; Kochanowicz, M.; Zmojda, J.; Miluski, P.; Dorosz, D. Study of mid-infrared emission and structural properties of heavy metal oxide glass and optical fibre co-doped with $\mathrm{Ho}^{3+} / \mathrm{Yb}^{3+}$ Ions. Materials 2019, 12, 1238. [CrossRef]

33. Pang, T.; Jian, R.H.; Xie, J.P.; Lu, W.H. Up-conversion luminescence and photo-thermal effect of $\mathrm{KY}_{3} \mathrm{~F}_{10}: \mathrm{Yb}^{3+}, \mathrm{Ho}^{3+}$ nanocrystals. J. Phys. D Appl. Phys. 2018, 51, 355301. [CrossRef]

34. Liu, F.; Deng, D.; Wu, M.; Chen, B.; Zhou, L.; Xu, S. Luminescent and thermometric properties of dual emitting $\mathrm{Eu}^{2+} / \mathrm{Sm}^{3+}$ co-doped $\mathrm{Sr}_{4} \mathrm{La}\left(\mathrm{PO}_{4}\right)_{3} \mathrm{O}$ phosphor based on energy transfer. J. Rare. Earth 2021, 39, 261-268. [CrossRef]

35. Jiao, M.; Xu, Q.; Zhao, Y.; Wang, D.; Liu, L.; Yang, C. Photoluminescence properties and energy transfer of high thermal stable $\mathrm{Na}_{2} \mathrm{GdPO}_{4} \mathrm{~F}_{2}: \mathrm{RE}\left(\mathrm{RE}=\mathrm{Sm}^{3+}, \mathrm{Ce}^{3+}, \mathrm{Tb}^{3+}\right)$ phosphor for solid-state lighting. J. Lumin. 2020, 226, 117388. [CrossRef]

36. Park, K.; Hakeem, D.A.; Pi, J.W.; Kim, S.W. Improvement of photoluminescence properties of $\mathrm{Ce}^{3+}-\mathrm{doped} \mathrm{CaSrAl}_{2} \mathrm{SiO}_{7}$ phosphors by charge compensation with $\mathrm{Li}^{+}$and $\mathrm{Na}^{+}$. Ceram. Int. 2018, 44, 1929-1934. [CrossRef]

37. Park, K.; Hakeem, D.A.; Pi, J.W.; Jung, G.W. Emission enhancement of Eu ${ }^{3+}$-doped ZnO by adding charge compensators. J. Alloys Compd. 2019, 772, 1040-1051. [CrossRef]

38. Guo, L.; Wang, Y.; Wang, Y.; Zhang, J.; Dong, P.; Zeng, W. Structure, enhancement and white luminescence of multifunctional $\mathrm{Lu}_{6} \mathrm{O}_{5} \mathrm{~F}_{8}: 20 \% \mathrm{Yb}^{3+}, 1 \% \mathrm{Er}^{3+}\left(\mathrm{Tm}^{3+}\right)$ nanoparticles via further doping with $\mathrm{Li}^{+}$under different excitation sources. Nanoscale 2013, 5, 2491-2504. [CrossRef] [PubMed]

39. Halubek, G.K.; Szymanski, D.; Tran, T.; Ferrari, M.; Lukowiak, A. Upconversion luminescence of silica-calcia nanoparticles co-doped with $\mathrm{Tm}^{3+}$ and $\mathrm{Yb}^{3+}$ Ions. Materials 2021, 14, 937. [CrossRef]

40. Bai, Z.H.; Lin, H.; Imakita, K.; Montazami, R.; Fujii, M.; Hashemi, N. Synthesis of $\mathrm{Er}^{3+} / \mathrm{Yb}^{3+}$ codoped NaMnF 3 nanocubes with single-band red upconversion luminescence. Rsc. Advances 2014, 4, 61891. [CrossRef]

41. Pollnau, M.; Gamelin, D.R.; Lüthi, S.R.; Güdel, H.U.; Hehlen, M.P. Power dependence of upconversion luminescence in lanthanide and transition-metal-ion systems. Phys. Rev. B 2000, 61, 3337-3346. [CrossRef]

42. Manoj, K.M.; Tristan, K.; Tanusree, M.; Christoph, B.; Kaushal., K.; Vineet, K.R.; Hans, H.; Ulrich, V. Incorporation of Zn ${ }^{2+}$ ions into $\mathrm{BaTiO}_{3}: \mathrm{Er}^{3+} / \mathrm{Yb}^{3+}$ nanophosphor: An effective way to enhance upconversion, defect luminescence and temperature sensing. Phys. Chem. Chem. Phys. 2015, 17, 20741.

43. Zhang, J.; Jin, C. Electronic structure, upconversion luminescence and optical temperature sensing behavior of $\mathrm{Yb}^{3+}-\mathrm{Er}^{3+} / \mathrm{Ho}^{3+}$ doped $\mathrm{NaLaMgWO}_{6}$. J. Alloys Compd. 2018, 783, 84-94. [CrossRef]

44. Zhang, T.; Yu, L.; Wang, J.; Wu, J. Microstructure and upconversion luminescence of $\mathrm{Yb}^{3+}$ and $\mathrm{Ho}^{3+}$ co-doped BST thick films. J. Mater. Sci. 2010, 45, 6819-6823. [CrossRef]

45. Vishwakarma, P.K.; Rai, S.B.; Bahadur, A. Intense red and green emissions from $\mathrm{Ho}^{3+} / \mathrm{Yb}^{3+}$ co-doped sodium gadolinium molybdate nano-phosphor: Effect of calcination temperature and Intrinsic optical bistability. Mater. Res. Bull. 2021, $133,111041$. [CrossRef] 